\title{
20th Anniversary of the Bologna Declaration: From overview of processes to ongoing activities and experiences
}

\author{
Luigi F. Donà dalle Rose \\ Editor
}

Anna Serbati

Assistant Editor

doi: http://dx.doi.org/10.18543/tjhe-6(2)-2019pp13-19

The present Issue comes to the light in May 2019, exactly twenty years after the signing of the Bologna Declaration on May $19^{\text {th }}$, 1999. For this important event, the Editorial Team of TJHE planned to edit an Anniversary Issue. Meanwhile, the Tuning Academy has also published an impressive book "REFORM! TUNING the Modernisation Process of Higher Education in Europe", ${ }^{1}$ by Robert Wagenaar, Director of the University of Groningen branch of the International Tuning Academy and cofounder of Tuning. Those interested in knowing more about the last three decades of HE policies in Europe will find real pleasure in reading those pages.

In such a context, the present Issue relies on two invited papers, plus some ordinarily submitted manuscripts, which witness a grass-root situation, rich in critical awareness and creativeness. Both types of papers were subjected to our standard double blind peer review procedure.

Before describing the content of this Issue, we would like, as Editors having quite different ages, to share the way in which we experienced the overall process following the Bologna Declaration.

One of us, the Editor, was Delegate and Consultant of the Rector of Padua University for the European mobility since 1990 for about 25 years. He took active part in the grass-root work, which at first paved the way to the Bologna Process and which then accompanied the several steps of that very process. This work was grounded in the international relations of an historical European University, but it was inspired by the fresh European winds that, at the beginning the Erasmus programme, were blowing everywhere. One of

${ }^{1}$ Robert Wagenaar, REFORM! TUNING the Modernisation Process of Higher Education in Europe: A Blueprint for Student-Centred Learning (Bilbao and Groningen: International Tuning Academy, 2019). Also accessible through the University of Groningen. Accessed May 8, 2019, https://www.rug.nl/research/portal/files/75936039/Complete_thesis.pdf. 
the most rewarding initial memories was the participation in the Toulouse Meeting (early '90s), when ECTS was endorsed by the European Commission as the official transfer tool for the recognition of the studies carried out abroad by Erasmus students. On that occasion, he first felt immersed in the community of European projects' "lovers and actors". After that, his "European" activity was a continuous effort in trying to find feasible ways at institutional and administrative level to translate in life practice, in a word to implement, the goals put forward by Erasmus and by the many other subsequent and complementary programmes. The Bologna Declaration thrusted this commitment, giving new enthusiasm. Participation in Tuning, CoRe2 and other EU projects followed. Often a question popped up among ourselves: Why am I doing all that? It is difficult to answer in a simple way. Many elements where there: the hope to improve the university life of our country, whose academic "weaknesses" were at first confirmed to our eyes by the euro-comparisons; the wish to be live actors in a hopefully farreaching path, the zest to feel in the forefront of an epochal process, the joy of meeting and sharing all this with many willing, enthusiastic and quite expert people, from many different countries. But perhaps the most gratifying thing was that we liked this type of commitment, the wish to make bridges between people, degree courses, institutions, often to be simply a "gobetween", i.e. between people looking for cooperating together. In this manner, we met several of the leading actors in the play, who reassured and inspired us: we exchanged ideas with them, we grew up and we were prepared to go further.

The other one, the Assistant Editor, is currently assistant professor at Padua University and benefited - as a student before than as a professor-of the Bologna Process and its related national reforms. First of all, she attended the university after the implementation of the system establishing bachelor/ master/doctoral degree in Adult Education. She could experience the progressive and growing level of deepness through the qualifications in understanding the disciplines and their application in the real working contexts, starting from the basis towards more detailed knowledge and more robust competences. One of the most crucial experiences she had during higher education studies was a 5-months Erasmus exchange in London, which represented for her a key milestone in her professional and personal growth. During her Ph.D. in Educational and Training Sciences, she had the chance to actually study the implementation of the Bologna Process in national and institutional reforms and to participate to innovative projects at Padua University as well as to Tuning initiatives. From studying the Tuning philosophy and concepts in books she moved to implementing them with 
international colleagues, enjoying the reflection, the sharing, the opportunity for debating and trying to innovate teaching, learning and assessment in higher education towards student centered perspectives and competencebased approaches. These opportunities fostered her passion in higher education evolutions and innovations and she became involved also in several staff development initiatives for academics at national and international level, with a specific focus on programme and syllabus design, planning and assessment.

The two invited contributions offer complementary "voices" on the process started with the Bologna Declaration: a passionate voice from the Council of Europe and a solid and informative voice from the EU academic and institutional communities.

The author of the first invited contribution is Sjur Bergan, Head of the Education Department of the Council of Europe. Among his many achievements, we only remind here his book Qualifications: Introduction to a Concept $^{2}$ a source of inspiration for many of us in those past years. His present contribution focusses on EHEA, the European Higher Education Area, i.e. at first the aim and then the achievement of the Bologna Process. It offers the view of the Process, as seen from a Council of Europe perspective through an active participation of the author in the BFUG-Bologna Follow Up Group and its Board. The article is enriched by precious memories and author's perceptions. In order to describe the overall process, the author identifies six different subsequent phases along the sequence of the Bologna Ministerial meetings: launching of the Bologna Process, dynamical development and need for stocktaking, consolidation (ending in 2010 with the "transition" from the Bologna process to the European Higher Education Area), first phase of the established EHEA, concerns about EHEA and renewed optimism, debate about the character of the process. Then, the article presents in depth the actual content of the EHEA structural reforms, i.e. quality assurance (with the challenge of becoming "international"), recognition and qualification frameworks (where a possible challenge stems from online non-national qualifications). ${ }^{3}$ As to the challenges faced by the whole process, this author states that "The challenges in structural reforms lie more in implementation than in developing new structures and perhaps even

${ }^{2}$ Sjur Bergan, Qualifications: Introduction to a Concept (Strasbourg: Council of Europe Publishing Council of Europe Higher Education Series No. 6, 2007).

${ }^{3}$ See, among others, Borhene Chakroun and James Keevy, Digital Credentialing: Implications for the recognition of learning across borders (Paris: UNESCO, 2018). Also accessible through UNESCO Digital Library. Accessed May 8, 2019, https://unesdoc.unesco. org/ark:/48223/pf0000264428. 
developing new policies". He clarifies this point by presenting the discussion occurred in the BFUG about the character of the process, whether it is a voluntary and inspiring participation or rather it involves a serious commitment to implementing the EHEA reforms. The final part of the article deals with academic values (how to make them more "operational" within EHEA) and with the further challenges related to interaction with the rest of the world and to the internal governance (and credibility) of EHEA.

The second invited contribution comes from Maria Sticchi Damiani, who since the early ' 90 s acted extensively to promote international cooperation and European HE projects, Erasmus in particular. Apart from much more, as described in her bio-note, she was the official Italian representative in the BFUG since its start till 2014 and she coordinated the Italian team of the Bologna Promoters. According to one of the reviewers, her contribution "provides a solid and informative overview, on the history of the Bologna Process and the ramifications of its debates", particularly useful to younger generations. It describes the two decades following the Bologna Declaration according to a "conceptual thread", which identifies "the specific features which coexisted and overlapped during the process, although one or some of them seemed to prevail at each stage". Looking back at the whole process, she identifies three broad phases: a pre-process Cooperation phase strongly supported by the EU initiatives, Erasmus above all, followed by a Convergence phase dominated by the Ministerial Meetings of the rapidly increasing number of participating Countries and by the work of the BFUG, well supported by "international organizations and major stakeholders". She finally identifies a Change phase, intertwined with the second one, characterised by the actual reforms which took place with regard to HE in terms of national laws and coordinated initiatives in the participating countries. The three phases contributed in diversified ways to the development of a common asset of principles, actions, policies and tools, which are all described in detail. The conclusive part of her contribution is a reflection on the actual impact of the reforms at the grass-root level and on whether the reforms have been consistently implemented in the different countries. According to the author the still many missing bricks in this huge educational enterprise are now mainly in the hands of the academic communities and in their collaboration across the borders of the participating countries.

As a further comment to our presentation of these two precious and complementary overviews, the interested reader will find it rewarding to look at the two initial chapters of the above quoted book by Wagenaar. In particular, at the end of its second chapter, referring to the main present challenges to be faced by EHEA, the author adds - to the main challenges 
outlined above and in line with the Paris Communique of the Bologna Ministers - the huge challenge of an "extensive attention for innovative teaching and learning and pedagogical training and continuous professional development of higher education teachers". ${ }^{4}$

Following these two Europe-oriented overviews, we then present here an interesting point of view (based on a constructive criticism) about the state of affairs of Quality Assurance in Africa. The article by Lazarus Nabaho and Wilberforce Turyasingura, from Uganda Management Institute, offers in its introduction an overview of those processes regarding African Higher Education, which started at the beginning of 2000 years and which were/are promoting 'revitalising of higher education' (in the words of the recent African Union Commission's education strategic framework plans). Quality Assurance plays a crucial role in this effort. Indeed, the Conference of African Ministers of Education in 2007, led by "the desire to synchronise the diverse higher education systems which have roots in multiple national and colonial legacies across the region", adopted the African Higher Education Harmonisation Strategy, an overarching policy framework, which includes a whole set of instruments - named Pan-African Quality Assurance and Accreditation Framework (PAQAF) - related to the issue of academic quality. Among others, these instruments (some are still under development) include the African Standards and Guidelines for Quality Assurance (ASGQA) and the African Quality Rating Mechanism (AQRM). This latter provides a self-assessment tool to those Higher Education Institutions, which are willing to check their performance both at institutional- and at programmelevel. As an important part of this self-assessment, a given institution is asked to complete the "AQRM survey". Then, the core part of the present article describes the results of a content analysis of the AQRM survey questionnaire on the basis of Harvey and Green's conceptual model for defining quality in higher education. The discussion of the results emphasises the fact that the AQRM notion of quality focusses mostly on "fitness for purposes" and "exceptional". This induces the authors to highlight the aspects of academic quality, which are "latent" in AQRM and which-if included in the surveymight lead to a better QA instrument.

The following three contributions well fit the expectations and the challenges raised by the above invited papers.

The contribution by Giovanni Barbato, Roberto Moscati, and Matteo Turri focuses on the epochal changes occurring in university education and

${ }^{4}$ Wagenaar, REFORM! TUNING the Modernisation Process of Higher Education in Europe: A Blueprint for Student-Centred Learning, 107. 
on the changing nature of the teaching activity to answer to the social, cultural and economic challenges emerging in modern society.

The article deepens the process of change on the professional profile of academics in an increasing tension between the traditional teaching methods versus the learning styles and professional expectations of students. Authors offer first a theoretical overview of the topic, based on two dimensions, the teacher/university relationship and the teacher/student relationship, to investigate the evolution of the professional profile of academics as teachers on the basis of seven teaching practices identified in the literature. The main part of the article is then a case study from Italy, which can be interesting for wider audience in Europe and in the world. The above-mentioned teaching practices found in the literature were the main subject of 90 in-depth interviews with teachers in charge of modules in undergraduate courses; interviewees were academics at different career levels with at least three years of activity and with full responsibility of their modules.

The findings show that, besides some limits that are specific to professional bureaucracies, the support of universities is fundamental for the promotion of innovation in teachers' teaching practices, which are otherwise regulated and shaped only by their respective disciplinary communities.

The contribution by María José Bezanilla, Ana García-Olalla, Jessica Paños, and Manuel Poblete offers "a comprehensive model for the analysis of the implementation of competence-based learning (CBL) in Higher Education". Out of the present authors, two ones co-authored the book "Competence-based learning". ${ }^{5}$ In the introduction to this latter, the Tuning General Coordinators, who were welcoming the book itself among the Tuning publications, wrote: "This book shifts from design to implementation and it is as such a concrete example how to proceed. [...] this is a book which is prepared to accompany the process of change at a concrete university". The present article has the same flavour, offering to any interested higher education institution a tool able to reveal the degree of impact that CBL has in its own educational structure and activities. The tool is based on an accurate analysis of the relevant literature, mainly but not only in the Spanish and Latin America context, with the aim of finding criteria and indicators that can help to effectively assess the actual degree of implementation of CBL in a given institution. After a first selection of criteria and indicators based on the literature and with the collaborative effort of a team of experts, the authors identified seven dimensions which explore the degree of

5 Aurelio Villa Sanchez and Manuel Poblete Ruiz, eds., Competence-based learning. A proposal for the assessment of generic competences (Bilbao: Deusto University Press, 2008). 
implementation of CBL in HEIs. They are: national regulatory framework, HEI regulatory framework, design of degree qualifications, subject/module planning process, teaching/learning practices, and improvement cycle both at degree level and at subject/module level. As a whole, these seven dimensions are articulated in 18 evaluation criteria, each one of these latter being articulated in indicators (for a total of 96 indicators). The model is going to be tested in two Latin America universities during the next academic year.

The final contribution, by Marina De Rossi and Emilia Restiglian, describes the development of an interdisciplinary workshop of Visual Storytelling aimed at fostering documentation competences in students of a Primary Teaching master degree. The related methodology might inspire in the interested reader a useful strategy to promote digital skills in educational contexts. As one reviewer stated, "hybrid solutions are becoming more popular as time goes by. The authors describe an interesting rationale in terms of relation between these approaches and competency development. Even more, they relate them with 21 st century's competencies", addressing key relevant challenges that higher education is facing with digital transformation. More in detail, the article's workshop aimed at developing primary teacher's professional competences related to digital narrative documentation (with reference to real educational experiences observed at school), to be certified through the Open Badge system, and it was implemented in two university courses involving 32 students. Data collection required students to fill a semi-structured questionnaire at the end of the workshop. Other data came from a rubric used to evaluate Visual Storytelling products from three different points of view (students' self-assessment; university teachers; school teachers). The authors conclude that the authentic task proposed in the workshop stimulated students to using technologies creatively, critically, and reflectively. According to the students' opinion, the workshop also facilitated collaborative processes as well skills of selfassessment and the personalisation of learning. 


\title{
20th Anniversary of the Bologna Declaration: From overview of processes to ongoing activities and experiences
}

\author{
Luigi F. Donà dalle Rose \\ Editor
}

Anna Serbati

Assistant Editor

doi: http://dx.doi.org/10.18543/tjhe-6(2)-2019pp13-19

\section{Copyright}

Copyright for this article is retained by the Publisher. It is an Open Access material that is free for full online access, download, storage, distribution, and or reuse in any medium only for noncommercial purposes and in compliance with any applicable copyright legislation, without prior permission from the Publisher or the author(s). In any case, proper acknowledgement of the original publication source must be made and any changes to the original work must be indicated clearly and in a manner that does not suggest the author's and or Publisher's endorsement whatsoever. Any other use of its content in any medium or format, now known or developed in the future, requires prior written permission of the copyright holder. 